Research Article

\title{
Subcritical Water Extraction of Antioxidants from Curculigo latifolia Root
}

\author{
Nur Athirah Zabidi $\mathbb{D}^{1},{ }^{1}$ Nur Akmal Ishak $\mathbb{D}^{1,2}$ Muhajir Hamid ${ }^{10},{ }^{3}$ and Siti Efliza Ashari ${ }^{2,4}$ \\ ${ }^{1}$ Laboratory of Molecular Biomedicine, Institute of Bioscience, Universiti Putra Malaysia (UPM), 43400 Serdang, \\ Selangor, Malaysia \\ ${ }^{2}$ Centre of Foundation Studies for Agricultural Science, Universiti Putra Malaysia (UPM), 43400 Serdang, Selangor, Malaysia \\ ${ }^{3}$ Department of Microbiology, Faculty of Biotechnology and Molecular Science, Universiti Putra Malaysia (UPM), 43400 Serdang, \\ Selangor, Malaysia \\ ${ }^{4}$ Integrated Chemical Biophysics Research, Faculty of Science, Universiti Putra Malaysia (UPM), 43400 Serdang, \\ Selangor, Malaysia \\ Correspondence should be addressed to Nur Akmal Ishak; nur_akmal@upm.edu.my
}

Received 28 December 2018; Revised 10 July 2019; Accepted 20 August 2019; Published 18 September 2019

Academic Editor: Leonardo Palmisano

Copyright (c) 2019 Nur Athirah Zabidi et al. This is an open access article distributed under the Creative Commons Attribution License, which permits unrestricted use, distribution, and reproduction in any medium, provided the original work is properly cited.

\begin{abstract}
This study aims to extract antioxidant compounds from Curculigo latifolia root by subcritical water extraction (SWE). The influence of extraction temperature and time on the antioxidant activity of C. latifolia root extract was investigated in terms of extraction yield, total phenolic content (TPC), total flavonoid content (TFC), 2, 2' -azino-bis-3-ethylbenzothiazoline-6-sulphonic acid (ABTS), and 1,1-diphenyl-2-picrylhydrazyl (DPPH) radical. The highest extraction yield (36.5\%), TPC (92.55 mg GAE/g), TFC (13.26 mg RE/g), and antioxidant activities by ABTS (66.8 mg trolox equivalent/g sample) and DPPH (128.7 mg trolox equivalent/g sample) were detected at $180^{\circ} \mathrm{C}$ and 30 minutes extraction time. Based on the results, the optimum condition was selected at $180^{\circ} \mathrm{C}$ and 30 minutes of extraction. The sample was screened by using liquid chromatography-mass spectrometry (LCMS) analysis where the phenolic compounds detected were structured based on their $[\mathrm{M}-\mathrm{H}]$-peak. The detected phenolic compounds were monobenzone, hydroquinone, phloridzin, pomiferin, mundulone, scandenin, and dimethyl caffeic acid. According to these findings, SWE is a promising, environmentally friendly, and efficient technology in the exploitation of natural products for the development of food and nutraceutical commodities.
\end{abstract}

\section{Introduction}

Phenolic compounds derived from natural sources have been associated with health benefits due to their antioxidant properties [1]. Several studies have shown that these natural antioxidants can be used to treat and prevent different types of diseases including cancer, hypertension, inflammation, degenerative disorders associated with ageing, and diabetes mellitus $[2,3]$. In fact, all of these diseases are mainly caused by excessive production of reactive oxygen species (ROS) and an imbalanced proportion between antioxidant and ROS in the human body [4]. Several mechanisms of antioxidant action revealed that these mechanisms can be divided into two classes, which are preventive antioxidants and chain-breaking antioxidants that allow them to reduce and scavenge the radicals in order to alleviate the disease [5]. Furthermore, processed food that has synthetic antioxidants must be developed as a healthy product that naturally contains many kinds of health benefits [6]. In addition to these, consumption of a nutritional plant-based diet will play an important role in decreasing or managing the incidence of chronic disease including diabetes mellitus, cancer, Alzheimer's disease, and even ageing [7].

In the last few decades, the conventional extraction technique of using different organic solvents was used to isolate phenolic compounds from natural sources. Recently, there is an increasing awareness to limit the uses of organic solvents in extracting natural sources for therapeutic 
activities due to the hazardous effect on human health caused by the residue from these hazardous solvents remaining in the final product [8]. Additionally, optimization of the extraction parameter must be investigated in order to preserve the structure of the extracted compounds. Hence, much interest has shifted towards the use of novel extraction techniques that are more environmentally safe than conventional extraction methods [9]. Subcritical water extraction (SWE) is one of the newest methods of extraction that can significantly increase the quality of the extracts and happens to be one of the extraction techniques that are favourable in extracting bioactive compounds from different kinds of natural sources [10]. This newest technology has been developed in an attempt to develop a cost-effective process, ensuring greater sustainability, safety, and quality of the products over conventional extraction techniques [11]. Basically, subcritical water extraction (SWE) uses water as the solvent in extracting phenolics using a temperature-dependent dielectric constant [12]. The polarity decreases with the increase of water temperature and throughout the whole process of extraction, input of high pressure is enough to maintain water in a liquid state [13]. In this work, the influence of temperature was investigated and optimized in the SWE of phenolic compounds from C. latifolia.

Curculigo latifolia Dryand. ex W. T. Aiton, is a rhizome geophyte that is categorised under the family Hypoxidaceae [14]. There are approximately 20 known species of Curculigo. Some of these species are said to have medicinal properties, such as acting as an anticancer agent and preventing gastrointestinal, cardiovascular, and heart-related diseases [15]. In our previous study, C. latifolia, which can be found in West Malaysia, was shown to exhibit antidiabetic properties in diabetic-induced rats. Nutrigenomic properties found in the fruit and root sections of $C$. latifolia that regulate responsible genes in glucose metabolism have been determined. All of the results demonstrate a high potential use of $C$. latifolia in diabetic therapy [16]. Additionally, the root has been certified to contain various compounds, such as cinnamic acid and benzoic acidderived and flavonoid-derived compounds such as hesperetin, apigenin, dryopteric acid, and isorhamnetin [17]. According to the available literature, there were no reports on the use of SWE for the recovery of the bioactive compounds from C. latifolia. Thus, the aim of this study was to evaluate the efficiency of SWE for obtaining C. latifolia extract by varying on the effect of temperature and time of extraction in determining the extraction yield, total phenolic content (TPC), total flavonoid content (TFC), and antioxidant activities including $2,2^{\prime}$-azinobis-3-ethylbenzothiazoline-6-sulphonic acid (ABTS) and 1,1diphenyl-2-picrylhydrazyl (DPPH) radical.

\section{Materials and Methods}

2.1. Plant Materials. The C. latifolia plant was collected in Selangor, Malaysia. A voucher specimen of the plant (SK 1709/09) was confirmed and deposited in the Biodiversity Unit, Institute of Bioscience, Universiti Putra Malaysia, Serdang, Selangor, Malaysia. The roots were cleaned with tap water and subsequently dried overnight in an oven at $40^{\circ} \mathrm{C}$.
The dried roots were ground into a fine powder that passed through a 30-mesh sieve. The sieved powdered roots were sealed and kept at $4^{\circ} \mathrm{C}$ for future analysis.

2.2. Materials and Reagents. Methanol, acetonitrile, and formic acid were of HPLC grade and purchased from Merck (Darmstadt, Germany). Folin-Ciocalteu reagent, 2,2-diphenyl-1 picrylhydrazyl hydrate (DPPH), sodium carbonate $\left(\mathrm{Na}_{2} \mathrm{CO}_{3}\right)$, aluminium chloride $\left(\mathrm{AlCl}_{3}\right)$, trolox, rutin, 2,2' -azino-bis-3ethylbenzothiazoline-6-sulphonic acid (ABTS), and potassium persulphate were obtained from Sigma-Aldrich (Steinheim, Germany). Methanol and ethanol were purchased from Merck (Darmstadt, Germany). All other chemicals were of analytical grade purity. All aqueous solutions were prepared using ultrapure water.

\subsection{Subcritical Water Extraction. Subcritical water extrac-} tion (SWE) was carried out using a batch system comprised of a SEPAREX piston pump (P200 LGP50, France), an electrical control panel, and an extraction vessel. The total capacity of the high-pressure stainless steel vessel volume was $50 \mathrm{ml}$, and thus it was filled with about $2 \mathrm{~g}$ of the $C$. latifolia root. The independent variables were temperature $\left(100,150,180\right.$, and $\left.200^{\circ} \mathrm{C}\right)$ and time $(30,60,90$, and $120 \mathrm{~min})$, while all other parameters were held constant. These independent variables were comprising extraction pressure (100 bar), flow rate $(0.5 \mathrm{ml} / \mathrm{min})$, and the water to solvent ratio $(1: 10 \mathrm{w} / \mathrm{v})$. After extraction, the extraction vessel was cooled and depressurized. The obtained extracts were concentrated to dryness using a freeze dryer to remove water completely, and the pure extract was stored in a dark place at $4^{\circ} \mathrm{C}$ until used for analysis.

2.4. Determination of Total Phenolic Content. The total phenolic content (TPC) of C. latifolia root extract was measured according to the method reported by [17], using the Folin-Ciocalteu reagent with some modification. The crude extract was mixed with $0.5 \mathrm{~mL}$ of Folin-Ciocalteu's phenol reagent and $7.5 \mathrm{~mL}$ of deionized water. The mixture was kept at room temperature for $10 \mathrm{~min}$ before $1.5 \mathrm{~mL}$ of $20 \%(\mathrm{w} / \mathrm{v})$ sodium carbonate was added [18]. Absorbance was measured at $765 \mathrm{~nm}$ using a microplate reader by a $96-$ well plate. Amounts of TPC were calculated using the gallic acid calibration curve within the range of 10-100 ppm [18]. Results were expressed as GA equivalents per gram of dry extract (mg GAE/g DE). All samples were analysed in triplicate and results averaged.

2.5. Determination of Total Flavonoid Content. Total flavonoid content (TFC) of the extracts was determined by the colourimetric assay following the procedure outlined in [19] with some modification. In brief, $100 \mu \mathrm{L}$ of the properly diluted sample $(1 \mathrm{~g}$ in $10 \mathrm{~mL})$ was reacted with $2 \% \mathrm{AlCl}_{3}$ for $10 \mathrm{~min}$ at room temperature in a 96-well plate. Rutin was used as a positive control, and the TFC of the samples was expressed as milligram rutin equivalents (mg RE)/g sample. All samples were analysed in triplicate and results averaged. 


\subsection{Determination of Antioxidant Activity}

2.6.1. DPPH Free Radical Scavenging Activity. The DPPH free radical scavenging activity of the sample was determined following the procedure described with minor modifications [19]. In short, $50 \mu \mathrm{L}$ of diluted samples was reacted with $200 \mu \mathrm{L}$ of $0.1 \mathrm{mM}$ DPPH radical methanolic solution in a 96well plate, gently swirled, and incubated in dark for $1 \mathrm{~h}$. Absorbance was measured at $765 \mathrm{~nm}$ using a microplate reader by a 96-well plate. The percentage inhibition of the samples was calculated, and samples were expressed as milligram trolox equivalents (mg TE)/g sample where trolox was used as a positive reference.

2.6.2. ABTS Radical Cation Scavenging Activity. The ABTS radical cation scavenging activity was measured according to the methods with minor modifications [19]. The ABTS radical cation was generated by mixing $1 \mathrm{~mL}$ of $7 \mathrm{mmol} / \mathrm{L}$ ABTS stock solution with $1 \mathrm{~mL}$ of $2.45 \mathrm{mmol} / \mathrm{L}$ potassium persulate for $12 \mathrm{~h}$ in the dark at room temperature. The mixture was subsequently diluted with deionized water to form a solution with a final absorbance of $0.70 \pm 0.02$ at $734 \mathrm{~nm}$. The scavenging activity was determined by reacting $20 \mu \mathrm{L}$ of the properly diluted sample with $200 \mu \mathrm{L}$ of the adjusted ABTS radical cation solution in a 96-well plate. The absorbance of the sample mixture was recorded at $734 \mathrm{~nm}$ after $10 \mathrm{~min}$ using a microplate reader by a 96 -well plate. The percentage inhibition of the samples was calculated and expressed as milligram trolox equivalents (mg TE)/g sample where trolox was used as a positive reference.

2.7. Liquid Chromatography-Mass Spectrometry (LC-MS) Analysis. LC-MS analysis was performed using an MS-QTOF mass spectrometer (Agilent Technologies, Santa Clara, USA) coupled to an HPLC system (Agilent Technologies, Santa Clara, USA). A C18 column $(125 \times 2 \mathrm{~mm}$ i.d., $5 \mu \mathrm{m}$ particle size) was used. The mobile phase was composed of water (A, 6\% acetic acid) in acetonitrile (B, 1\% acetic acid), and the gradient programme of which was $2-5.00 \mathrm{~min}, 95$ to $75 \% \mathrm{~A}$ and 5 to $25 \% \mathrm{~B} ; 5-10.00 \mathrm{~min}, 60 \% \mathrm{~A}$ and $40 \% \mathrm{~B}$; $15.00 \mathrm{~min}, 50 \% \mathrm{~A}$ and $50 \% \mathrm{~B}$; and finally $20.00 \mathrm{~min}, 50 \% \mathrm{~A}$ and $50 \% \mathrm{~B}$. The injection volume of the sample was $10 \mu \mathrm{L}$, and the flow rate of mobile phase was $0.5 \mathrm{~mL} / \mathrm{min}$. The chromatographic column was kept at $30^{\circ} \mathrm{C}$. For MS analysis of samples, the following settings were used according to the procedure described with minor modification [20]: CID gas pressure to 2.40 mTorr, EIS needle voltage to $1000 \mathrm{~V}$, EIS shield voltage to $600 \mathrm{~V}$, drying gas temperature to $200^{\circ} \mathrm{C}$, API housing temperature to $50^{\circ} \mathrm{C}$, nebulizer gas pressure to $35 \mathrm{psi}$, and drying gas pressure to $40 \mathrm{psi}$. The flavonoids and other phenolic compounds in were identified based on the mass spectra and by comparison of the spectra of available standards.

2.8. Statistical Analysis. The extraction yields of the sample were calculated from the calibration curves of the standard compounds. The data were expressed as mean $\pm \mathrm{SD}$ values.
The Prism 7 was used for statistical analyses. The cutoff for a significant variation was $p<0.05$ in Duncan's test. Spearman's rank correlation coefficients were calculated in order to characterize the relationship between antioxidant capacities detected by different assays for phenolic and flavonoid contents.

\section{Results and Discussion}

3.1. Influence of Process SWE Variables on the Extraction Yield. The extraction yields, total phenolic content, and total flavonoid content of the extracts obtained at different extraction conditions of temperature and time are presented in Table 1. Determining the yield is an essential step in order to determine the total extracted sample over the raw sample. Based on the results, the yield varied from $14.2 \mathrm{~g} / 100 \mathrm{~g}$ to $36.5 \mathrm{~g} / 100 \mathrm{~g}$. The highest yields were achieved at $180^{\circ} \mathrm{C}$ although the differences were not significant in some cases. The increase in temperature also leads to the increase of yield for all different times. The yield varied from 14.0 to $36.5 \mathrm{~g} /$ $100 \mathrm{~g}$ of the sample extract. The obvious yield was noticed for the first $30 \mathrm{~min}$ of extraction time at every extraction temperature. Additionally, at $100^{\circ} \mathrm{C}$, a significant difference was noted between 30 and $60 \mathrm{~min}$, but there is no significant difference in the result after that until it reached $120 \mathrm{~min}$. All the yields were noted to increase from $30-120 \mathrm{~min}$ at $150^{\circ} \mathrm{C}$, and simultaneously the amount of extracted sample was also increased to $26.5 \mathrm{~g} / 100 \mathrm{~g}$ at $180^{\circ} \mathrm{C}$ with $30 \mathrm{~min}$ extraction time which was noted as the highest yield obtained.

In addition, at $200^{\circ} \mathrm{C}$ with $120 \mathrm{~min}$ extraction times, the yield was only $12.0 \mathrm{~g} / 100 \mathrm{~g}$ of the dried root extract, which was recorded as twofold lower than the yield at the optimum condition. However, a significant difference was noticed at $180^{\circ} \mathrm{C}$ from different extraction times. In theory, a higher temperature causes a reduction of polar forces and hydrogen bonding between water molecules and this also reduces water polarity as well. At a high temperature, there is a possibility for the solution to become saturated with the solute, which can affect the mass transfer rate and prevent the dissolution of solids into the solution and decreases the yield [10]. In fact, from the reduction of water density and viscosity, this resulted in an increased mass transfer of the solvent into the matrix of the sample. However, as the sample approaches $200^{\circ} \mathrm{C}$, there is a reduction of yield even after increasing the temperature. This fact was previously confirmed by Song et al., who stated that there was degradation of a compound as the temperature increases from $180^{\circ} \mathrm{C}$ to $210^{\circ} \mathrm{C}[21]$.

\subsection{Effect of Temperature and Time on TPC and TFC of Root} Extracts. The results in Table 1 also shows the total phenolic and flavonoid content obtained under SWE extraction conditions at various ranges of temperatures and times. Under each of the conditions, the phenolic and flavonoid compound was measured for every $30 \mathrm{~min}$. The content of extractable phenolic compounds in the root of C. latifolia extract was determined through a linear gallic acid standard curve $\left(y=0.0156 x+0.0416, R^{2}=0.9962\right)$. The phenolic 
TABLE 1: Extraction yields, total phenolic content, and total flavonoid content of C. latifolia root extracts by subcritical water extraction (SWE) at different extraction conditions.

\begin{tabular}{|c|c|c|c|c|}
\hline Temperature $\left({ }^{\circ} \mathrm{C}\right)$ & Time (min) & Yield (g/100 g) & TPC (mg GAE/g) & TFC (mg RE/g) \\
\hline 100 & 30 & $18.4 \pm 0.31^{\mathrm{a}}$ & $34.43 \pm 0.25^{\mathrm{a}}$ & $5.72 \pm 0.81^{\mathrm{b}}$ \\
\hline 100 & 60 & $15.3 \pm 0.15^{\mathrm{b}}$ & $39.61 \pm 0.13^{\mathrm{a}}$ & $8.5 \pm 2.24^{\mathrm{a}}$ \\
\hline 100 & 90 & $14.2 \pm 0.11^{\mathrm{b}}$ & $38.79 \pm 0.14^{\mathrm{a}}$ & $9.79 \pm 1.17^{\mathrm{a}}$ \\
\hline 100 & 120 & $15.5 \pm 0.32^{\mathrm{b}}$ & $40.75 \pm 0.55^{\mathrm{a}}$ & $8.3 \pm 0.92^{\mathrm{a}}$ \\
\hline 150 & 30 & $25.35 \pm 0.68^{\mathrm{a}}$ & $72.89 \pm 1.14^{\mathrm{a}}$ & $7.83 \pm 0.38^{\mathrm{b}}$ \\
\hline 150 & 60 & $20.0 \pm 0.52^{\mathrm{b}}$ & $68.37 \pm 4.79^{\mathrm{ab}}$ & $6.99 \pm 0.51^{\mathrm{b}}$ \\
\hline 150 & 90 & $19.5 \pm 1.41^{\mathrm{b}}$ & $61.47 \pm 1.13^{\mathrm{b}}$ & $11.1 \pm 0.52^{\mathrm{a}}$ \\
\hline 150 & 120 & $21.8 \pm 0.38^{\mathrm{b}}$ & $64.60 \pm 3.22^{\mathrm{ab}}$ & $10.4 \pm 0.28^{\mathrm{a}}$ \\
\hline 180 & 30 & $36.5 \pm 0.91^{\mathrm{a}}$ & $92.55 \pm 2.83^{\mathrm{a}}$ & $13.26 \pm 0.3^{\mathrm{a}}$ \\
\hline 180 & 60 & $31.4 \pm 0.55^{\mathrm{b}}$ & $78.79 \pm 0.69^{b}$ & $11.05 \pm 1.3^{\mathrm{ab}}$ \\
\hline 180 & 90 & $22.6 \pm 0.49^{c}$ & $66.60 \pm 0.57^{\mathrm{c}}$ & $8.68 \pm 0.44^{\mathrm{b}}$ \\
\hline 180 & 120 & $23.5 \pm 0.11^{\mathrm{c}}$ & $48.58 \pm 0.57^{\mathrm{d}}$ & $9.08 \pm 0.3^{\mathrm{b}}$ \\
\hline 200 & 30 & $14.0 \pm 0.26^{\mathrm{b}}$ & $84.65 \pm 1.97^{\mathrm{a}}$ & $7.8 \pm 0.44^{\mathrm{b}}$ \\
\hline 200 & 60 & $16.0 \pm 1.48^{\mathrm{a}}$ & $87.97 \pm 0.13^{\mathrm{a}}$ & $10.71 \pm 0.4^{\mathrm{a}}$ \\
\hline 200 & 90 & $16.5 \pm 0.52^{\mathrm{a}}$ & $86.39 \pm 2.01^{\mathrm{a}}$ & $8.52 \pm 0.5^{\mathrm{ab}}$ \\
\hline 200 & 120 & $12.0 \pm 0.07^{\mathrm{c}}$ & $68.75 \pm 0.76^{\mathrm{b}}$ & $9.86 \pm 0.26^{\mathrm{ab}}$ \\
\hline
\end{tabular}

The values are expressed as mean \pm standard deviation $(n=3)$. Different letters in the same column indicate that the means differ significantly by the Tukey test $(p \leq 0.05)$. TPC: total phenolic content; TFC: total flavonoid content; GAE: gallic acid equivalents; RE: rutin equivalents.

content for root extracts varied from 34.43 to $92.55 \mathrm{mg} \mathrm{GAE} /$ g. The highest fraction of phenolic content was collected for the first $30 \mathrm{~min}(92.55 \mathrm{mg} \mathrm{GAE} / \mathrm{g})$ at $180^{\circ} \mathrm{C}$. In addition, while increasing the temperature, the phenolic content also increased. This finding is in agreement with other studies where it was reported that at $180^{\circ} \mathrm{C}$, the highest phenolic content (26.26 g/L) was obtained [22]. Nevertheless, when the temperature increased to $200^{\circ} \mathrm{C}$, the amount of phenolic content recovered decreased, and at this temperature, the lowest value of phenolic content was recorded $(68.75 \mathrm{mg}$ GAE/g) for 2 hours of extraction time. After achieving the highest phenolic and flavonoid compound, increasing the temperature will possibly lead to further degradation, and the reaction of some phenolic substances and the contribution of decreasing dielectric constant will make total phenolic content less effective [23]. Furthermore, a previous study reported by Erşan et al. observed that the degradation of the phenolic compound occurred above $180^{\circ} \mathrm{C}$ extraction temperature by qualitative confirmation with HPLC-DADESI/MS analysis for every extraction temperature condition [24]. Furthermore, the results show no significant difference at $200^{\circ} \mathrm{C}$ with the increasing of extraction time.

The TFC of C. latifolia root extract was evaluated by using the aluminium colourimetric method, and the rutin standard was used as a standard curve $(y=0.0074 x+0.0043$, $\left.R^{2}=0.9993\right)$. The flavonoid content of root extract varied from 5.72 to $13.26 \mathrm{mg} \mathrm{RE} / \mathrm{g}$. The highest quantity of flavonoid was obtained at $180^{\circ} \mathrm{C}$ in $30 \mathrm{~min}$ extraction times with $13.26 \mathrm{mg} \mathrm{RE} / \mathrm{g}$. The lowest flavonoid content was achieved during $30 \mathrm{~min}$ of extraction time at $100^{\circ} \mathrm{C}$. Starting from $100^{\circ} \mathrm{C}$, the flavonoid content increased until it reached the highest flavonoid fraction which was at $180^{\circ} \mathrm{C}$. Increases in the extraction temperature leads to sudden decreases on the water viscosity, water permittivity, and also surface tension but this will increase in its diffusivity properties. Additionally, SWE at higher temperatures increased the thermal agitation and hence, decreased the strength of the hydrogen bonds, which led to the more efficient extraction of nonpolar hydrophobic compounds compared with polar hydrophilic compounds [25].

In fact, as the temperature of the water increased less energy was needed to disrupt the solute matrix interactions in order to achieve the enhancement of solute contact with the solvent [26]. Afterwards, the flavonoid content decreased as the temperature reached $200^{\circ} \mathrm{C}$. So, it was easy to conclude that the bond in the flavonoid compound was unstable and began to break down as the temperature exceeded $200^{\circ} \mathrm{C}$. For the first $30 \mathrm{~min}$, the results showed a significant difference within the temperature range between $100^{\circ} \mathrm{C}$ and $180^{\circ} \mathrm{C}$. Furthermore, the total phenolic content obtained was sevenfold more compared with the total flavonoid content in the C. latifolia root extract. Additionally, the influence of extraction time on the efficiency of SWE was studied previously [27], and according to the conducted study, the first 30 min of extraction time was considered as the optimal extraction time of phenolic compounds. At this condition, the polarity of water is reduced to approach the property of organic components and then hydrolysis might occur. This may lead to degradation of the cell wall phenolic compounds in the lignin network and, under this condition, the dielectric constant of subcritical water $(\varepsilon=31)$ was close to the permittivity of ethanol $(\varepsilon=25)$ or methanol $(\varepsilon=33)$ [25].

In terms of achieving high phenolic and flavonoid content under SWE extraction, there is no previous study yet that can be compared to the study of the C. latifolia root which uses subcritical water extraction. But a previous study reported that under conventional extraction using aqueous fraction, the TPC and TFC obtained was $4.62 \mathrm{mg} \mathrm{GAE} / \mathrm{g}$ and $1.62 \mathrm{mg} \mathrm{RE} / \mathrm{g}$ extract, respectively, and for the $n$-butanol fraction, the TPC and TFC obtained was $24.96 \mathrm{mg} \mathrm{GAE} / \mathrm{g}$ and $10.84 \mathrm{mg} \mathrm{RE} / \mathrm{g}$ extract, respectively [28]. Thus, by comparing the results, it shows the TPC by SWE is fourfold higher compared with butanol fraction extracts. 
3.3. Total Antioxidant Capacity (TAC). For instance, phenols are well-known antioxidants while flavonoids are mostly known for their powerful free radical scavenging activity with strong antioxidant activity. The antioxidant activity of SWE of the C. latifolia root was measured using $\mathrm{DPPH}$ and ABTS assays, and a comparison was performed to understand the correlation of antioxidant activity with TPC and TFC values. The results for both antioxidant activities are displayed in Figures 1 and 2. In this study, the effect of temperature and time of SWE on antioxidant activities was determined. The DPPH radical scavenging activities ranged between 56.30 and $128.70 \mathrm{mg}$ trolox equivalents/g samples and the ABTS scavenging activity varied from 42.59 to $66.78 \mathrm{mg}$ trolox equivalents/g sample. In terms of process, DPPH scavenging activity increases as the temperature rises to $180^{\circ} \mathrm{C}$ and at $30 \mathrm{~min}$ under the same temperature exhibits the highest scavenging activity $(128.70 \mathrm{mg}$ trolox/g sample). The lowest free radical scavenging activity was recorded at $100^{\circ} \mathrm{C}$ and was also noted at 30 min of extraction time. Similarly, for the ABTS scavenging activity, the results indicate that as the temperature increased, the antioxidant activity also increased until it reached the maximum value at $180^{\circ} \mathrm{C}$ temperature. After that, antioxidant activity decreased when it approached $200^{\circ} \mathrm{C}$. Theoretically, maximum antioxidant activity was achieved at the optimum extraction temperature by donating high electron or hydrogen in scavenging the free radicals. Afterwards, the antioxidant activity gradually decreases as the temperature approaches $200^{\circ} \mathrm{C}$. Temperatures higher than $180^{\circ} \mathrm{C}$ give low antioxidant activity and, according to the literature, the main antioxidant constituents of the flavonoid compound will start degrading [29]. In addition, there is no significant difference reported at each temperature within the range from $100^{\circ} \mathrm{C}$ to $180^{\circ} \mathrm{C}$ for both antioxidant assays.

The DPPH and ABTS assay offered a cost-effective, efficient, and rapid solution in evaluating antioxidant assay based on calculating percentage inhibition which is equivalent with antioxidant capacity content in the sample. These applied methods are widely used in the evaluation of antioxidant abilities for both natural and synthetic molecules [30]. The smaller the concentration of antioxidants and the faster the antioxidant reacts with free radicals, the greater the scavenging activity [31]. According to the results of the scavenging activity by DPPH and ABTS assay, these extracts were significantly affected at various extraction temperatures and times. The result shows that the DPPH assay gives a twofold higher scavenging activity than the ABTS assay. This result is also supported by other previous studies that act under subcritical water extraction in which the trolox equivalent antioxidant capacity (TEAC) value is also twofold higher than the ABTS assay [32]. High TFC also can be one of the effective agents to scavenge free radicals by DPPH and also the ABTS assay [11]. From the observation at $200^{\circ} \mathrm{C}$, the result shows that for both assays there is no significant difference in scavenging activity as increasing extraction time. This proves that low amount of phenolic and flavonoid content cannot inhibit the free radical, resulting in low antioxidant value at this point.
3.4. Correlation of Antioxidant Activities in Terms of the Content of Total Phenolics, Flavonoids, and Phytochemicals. To investigate the factors that are responsible for the antioxidant activity of $C$. latifolia root extracts, correlation analysis was carried out with the total phenolic content, total flavonoid content, and antioxidant activity. The experimental results were verified using linear correlation analysis. The ABTS and DPPH values of the extracts followed a similar trend as for the total phenolic and flavonoid contents [18], and a strong correlation among all the phytochemicals and antioxidant activity was obtained (Table 2). Based on the results, the highest correlation coefficient of 0.819 and significant correlation $(p<0.001)$ was between DPPH and TFC. The slightly higher free radical scavenging activity of the aqueous extract indicates the presence of a higher content of flavonoids in the extracts. Besides, the TPC finding correlated well with the results of ABTS and DPPH assays. There was also a moderate positive correlation that has a significant correlation $(p<0.05)$ between ABTS and TPC in root extracts. These results suggest that the DPPH assay better reflects the antioxidant contents of the C. latifolia root extract for SWE than the ABTS assay for total phenolic and flavonoid content. This correlation between phenolic and antioxidant activity substantiates the well-known free radical scavenging potential of these natural products.

3.5. LC-MS Analysis. The LC-MS profile from the screening of C. latifolia root extract is shown in Figure 3 and peaks were labelled according to the order of their retention time as shown in Table 3. Several bioactive compounds were detected based on accurate masses and fragmentation pattern aided by the existing literature in the mass spectrometry libraries. In particular, these compounds were phenolic (monobenzone) and identified as phenolic from benzene derivative (hydroquinone), flavonoid glycoside (phloridzin), prenylflavonoids (pomiferin), isoflavonoid (mundulone and scandenin), and in particular cinnamic acid derivative (dimethyl caffeic acid).

The negative molecular ion at $[\mathrm{M}-\mathrm{H}]-$ for each of the targeted compound was also shown in Figure 4. The analysis of phenolic compounds was identified and characterized by the negative ionization mode [33]. In the analysis, the peak with a negative molecular ion at $[\mathrm{M}-\mathrm{H}]-$ at an $\mathrm{m} / \mathrm{z}$ of 109 was identified as hydroquinone. The second identified peak has shown an $\mathrm{m} / \mathrm{z}$ of 477 , indicating that this compound is phloridzin. The next peak exhibited an $\mathrm{m} / \mathrm{z}$ of 341 , which corresponds to monobenzone. The identified peak that had an $\mathrm{m} / \mathrm{z}$ of 433,477 , and 683 were corresponding to scandenin, pomiferin, and dimethyl caffeic acid, respectively. The mundulone compound corresponds to two $\mathrm{m} / \mathrm{z}$ value points which are 433 and 867 , respectively. Previous reports evidenced that the identified compounds are able to exert a strong antioxidant activity. In fact, from the previous study it shows that hydroquinone acts as an antioxidant and helps in the protection of human cells against oxidative damage, and it was also reported that the antioxidant activity of hydroquinone is mainly due to 


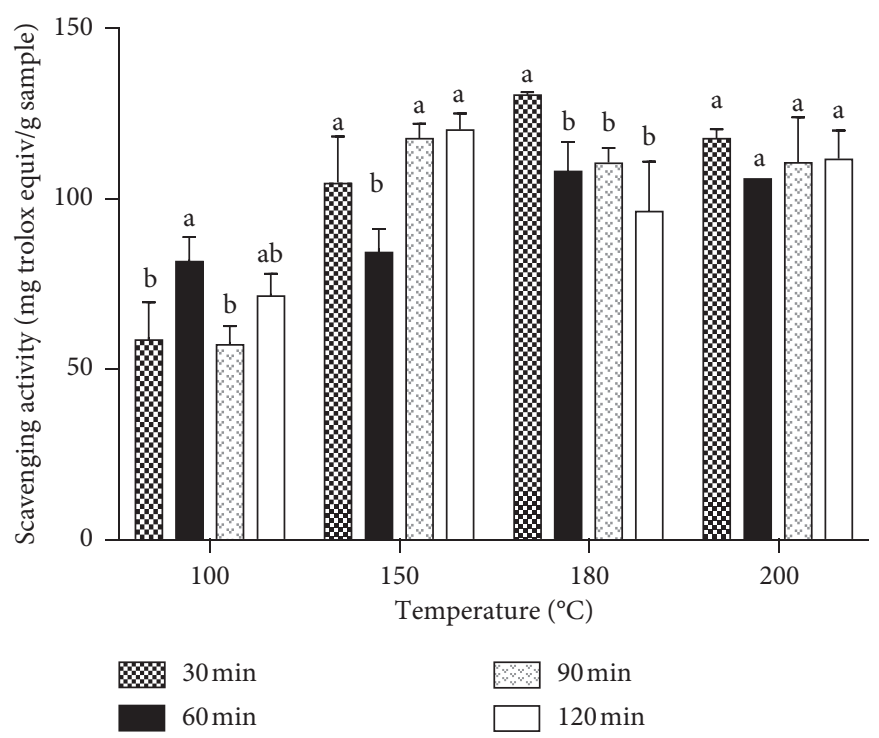

FIGURE 1: Effects of temperature and time on antioxidant activity (DPPH scavenging activity) of C. latifolia root extracts by SWE. Different letters indicate significant differences $(p<0.05)$ within the same extraction temperature.

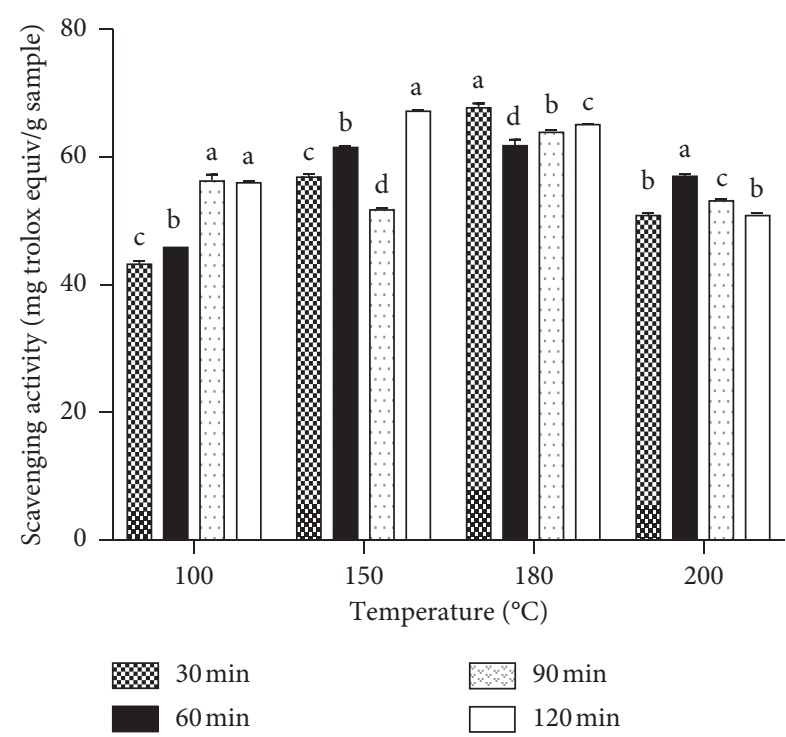

FIGURE 2: Effects of temperature and time on antioxidant activity (ABTS scavenging activity) of C. latifolia root extracts by SWE. Different letters indicate significant differences $(p<0.05)$ within the same extraction temperature.

the activity of $\mathrm{OH}$ and the functional group in its structure [34]. Isoflavones are a large group of phenolic compounds synthesized through the central phenylpropanoid pathway. Higher antioxidant capacities were mainly attributed to the increase in the concentration of isoflavones present in the sample and also due to the regulation of enzymes involved in the phenylpropanoid pathway which has been proposed as a plant defense mechanism against selenium-induced oxidative stress [35]. In addition, phloridzin is known as a flavonoid glycoside which belongs to the chemical class of dihydrochalcones, phenylpropanoids with structures closely related to those of the immediate flavonoid
TABLE 2: Correlations between TPC, TFC, ABTS, and DPPH of $C$. latifolia's extract.

\begin{tabular}{lcccc}
\hline$R$ & TPC & TFC & DPPH & ABTS \\
\hline TFC & $0.451^{*}$ & 1 & & \\
DPPH & $0.819^{* * *}$ & $0.591^{*}$ & 1 & \\
ABTS & $0.373^{*}$ & $0.512^{*}$ & $0.436^{*}$ & 1 \\
\hline
\end{tabular}

$R$ : correlation coefficient, TPC: total phenolic content, TFC: total flavonoid content, DPPH: 1,1-diphenyl-2-picrylhydrazyl, ABTS: 2,2'-azino-bis-3ethylbenzothiazoline-6-sulphonic acid. $\quad{ }^{*} p<0.05, \quad{ }^{* *} p<0.01$, and ${ }^{* * *} p<0.001$ compared to the control.

precursors, the chalcones [36]. Previous studies show that the phloridzin compound detected in the sample also contributes to the antioxidant activity, and it was discovered that phloridzin also decreases the absorption of glucose, thus reducing postprandial blood glucose levels; hence, this will be beneficial to the treatment of diabetes mellitus [37]. Besides, we also looked at other compounds as a side compound such as hordatine A, 3-methylsuberic acid, ubiquinone, frangulin $\mathrm{B}$, rubratoxin $\mathrm{B}$, and emmotin A that were also detected in the sample extract. Coenzyme Q10 or mostly known as ubiquinone, also identified as one of the nonenzymatic endogenous antioxidants, plays an important role in the cellular metabolism and acts as an antioxidant through preventing the formation of lipid peroxy radicals [6]. The LC-MS analysis was effective in the screening of important polyphenolic compounds that contribute to the antioxidant capacity of the C. latifolia root extract, as assessed by TPC, TFC, and antioxidant assays. In the present study, the antioxidant compounds such as phenolic derivatives of benzoic acid, cinnamic acid derivatives, and flavonoids were reported for the first time in the C. latifolia root extract. These findings can be one of the benchmarks to show that the SWE method is capable of extracting other valuable phenolics that were present in the crude extracts. The results given by the SWE method 


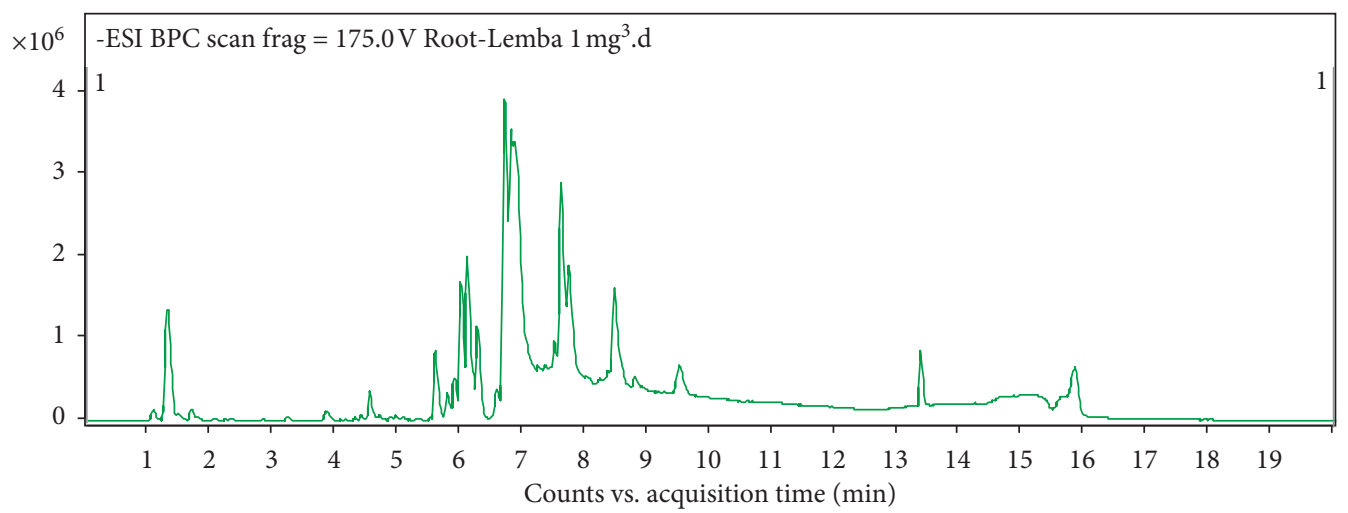

FIGURE 3: LC-MS chromatogram screening of the C. latifolia root extract.

TABle 3: LC-MS analysis of Curculigo latifolia root extract.

\begin{tabular}{|c|c|c|c|}
\hline Sample & Retention time (min) & Compound name & Formula \\
\hline Root extract & $\begin{array}{c}5.185 \\
5.916 \\
6.589 \\
6.725 \\
7.322 \\
7.529 \\
8.447 \\
10.74 \\
12.962 \\
13.07 \\
13.698 \\
15.95 \\
16.960\end{array}$ & $\begin{array}{c}\text { Phloridzin(phenolic) } \\
\text { Pomiferin(phenolic) } \\
\text { Scandenin(phenolic) } \\
\text { Mundulone(phenolic) } \\
\text { Monobenzone(phenolic) } \\
\text { Hydroquinone(phenolic) } \\
\text { Dimethyl caffeic acid(phenolic) } \\
\text { Hordatine A } \\
\text { 3-Methylsuberic acid } \\
\text { Ubiquinone } \\
\text { Frangulin B } \\
\text { Rubratoxin B } \\
\text { Emmotin A }\end{array}$ & $\begin{array}{ccc}\mathrm{C}_{21} & \mathrm{H}_{24} & \mathrm{O}_{10} \\
\mathrm{C}_{25} & \mathrm{H}_{24} & \mathrm{O}_{6} \\
\mathrm{C}_{26} & \mathrm{H}_{26} & \mathrm{O}_{6} \\
\mathrm{C}_{26} & \mathrm{H}_{26} & \mathrm{O}_{6} \\
\mathrm{C}_{13} & \mathrm{H}_{12} & \mathrm{O}_{2} \\
\mathrm{C}_{6} & \mathrm{H}_{6} & \mathrm{O}_{2} \\
\mathrm{C}_{11} & \mathrm{H}_{12} & \mathrm{O}_{4} \\
\mathrm{C}_{28} & \mathrm{H}_{38} & \mathrm{~N}_{8} \\
\mathrm{C}_{9} & \mathrm{H}_{16} & \mathrm{O}_{4} \\
\mathrm{C}_{14} & \mathrm{H}_{18} & \mathrm{O}_{4} \\
\mathrm{C}_{20} & \mathrm{H}_{18} & \mathrm{O}_{9} \\
\mathrm{C}_{26} & \mathrm{H}_{30} & \mathrm{O}_{11} \\
\mathrm{C}_{9} & \mathrm{H}_{10} & \mathrm{O}_{5}\end{array}$ \\
\hline
\end{tabular}

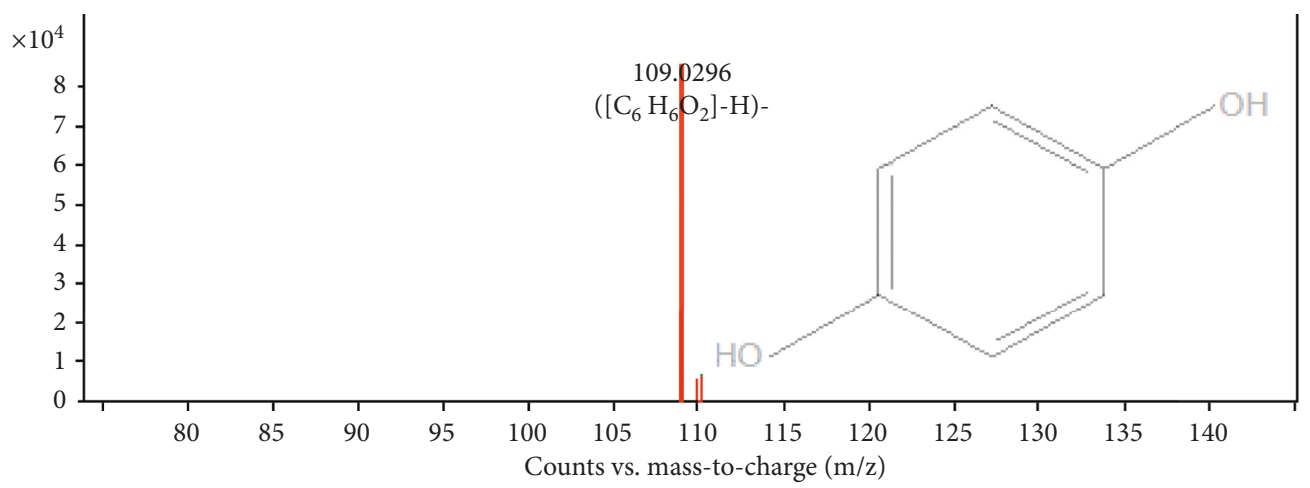

(a)

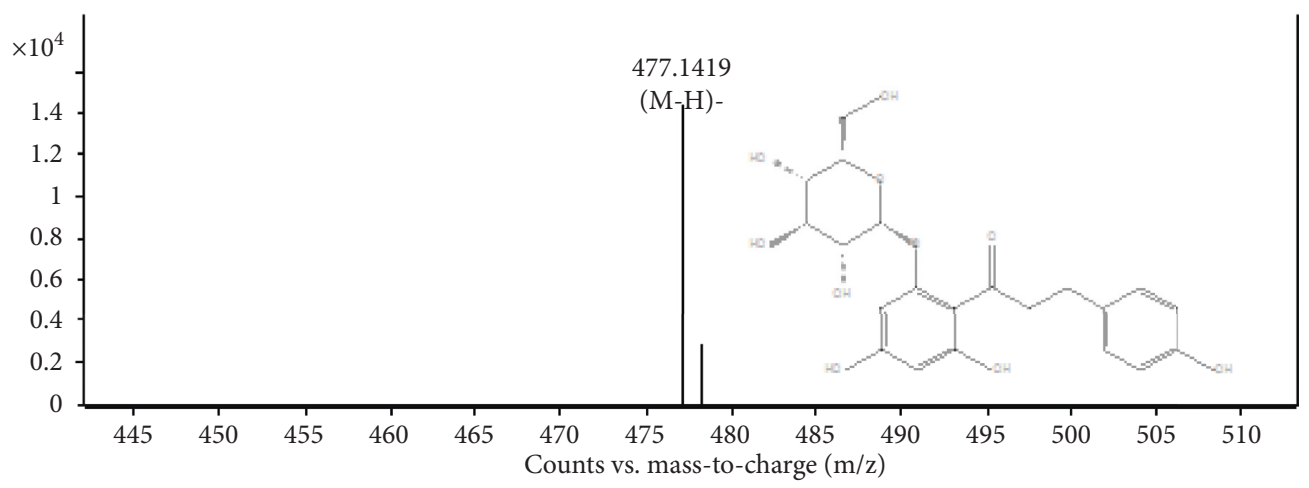

(b)

Figure 4: Continued. 


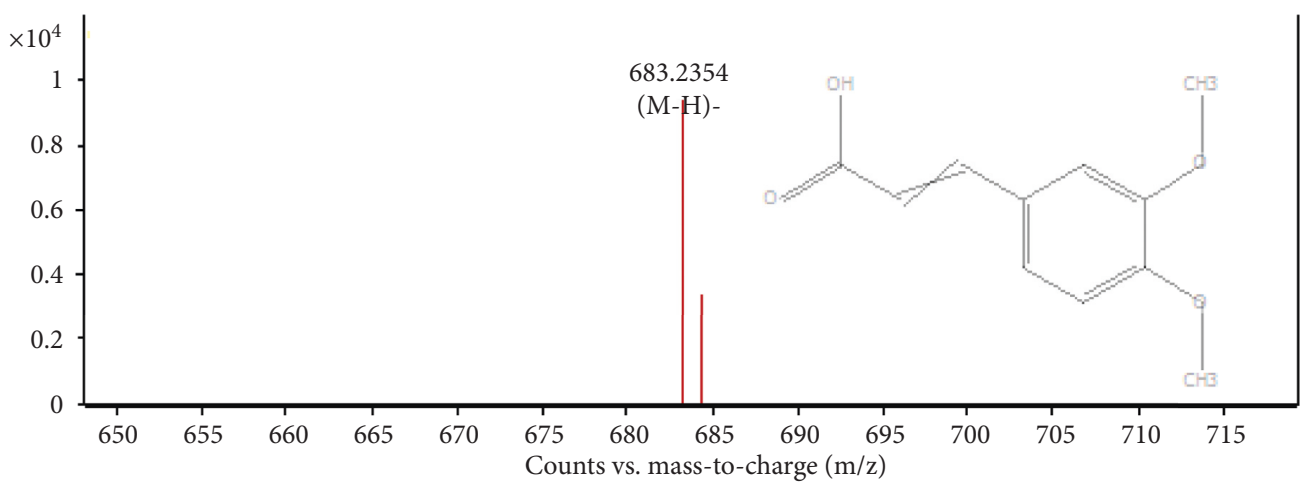

(c)

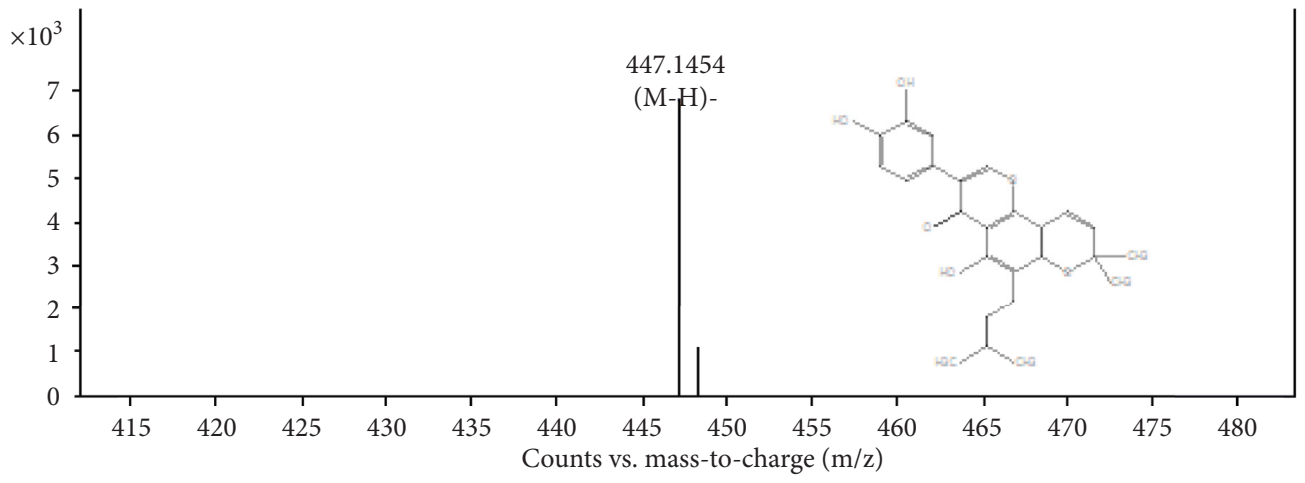

(d)

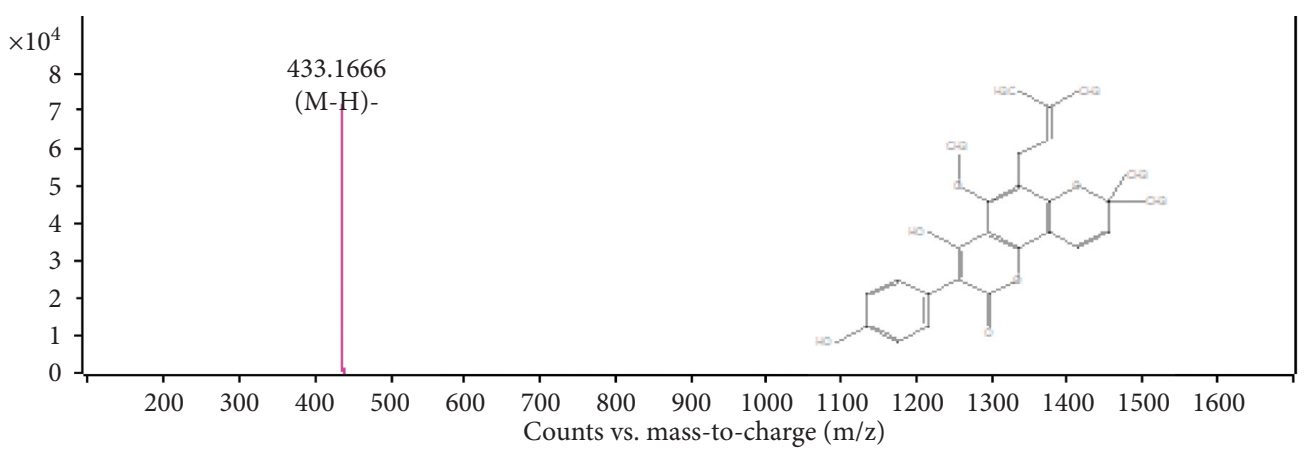

(e)

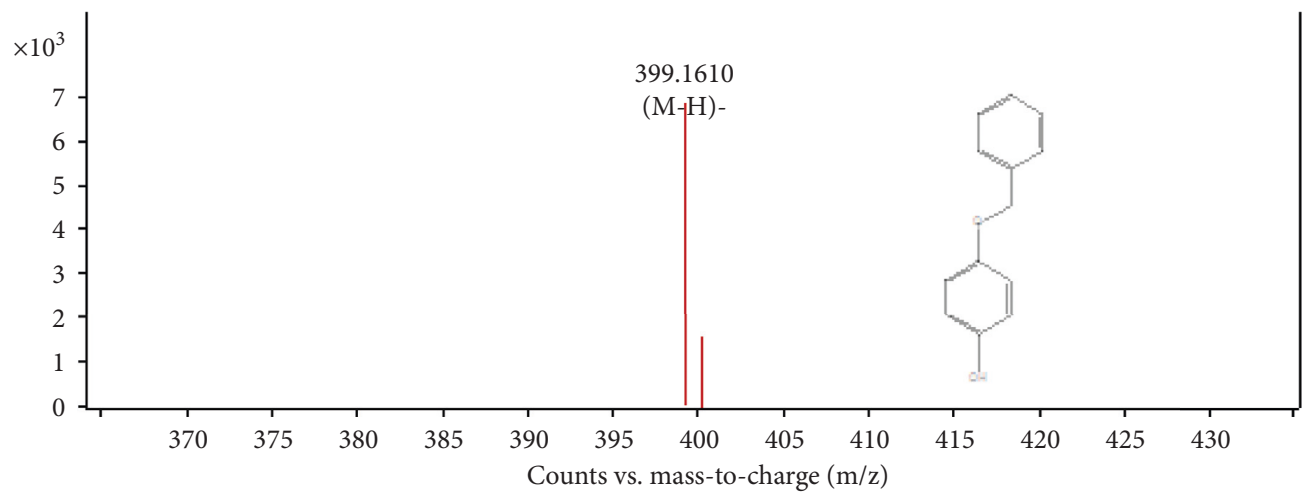

(f)

Figure 4: Continued. 


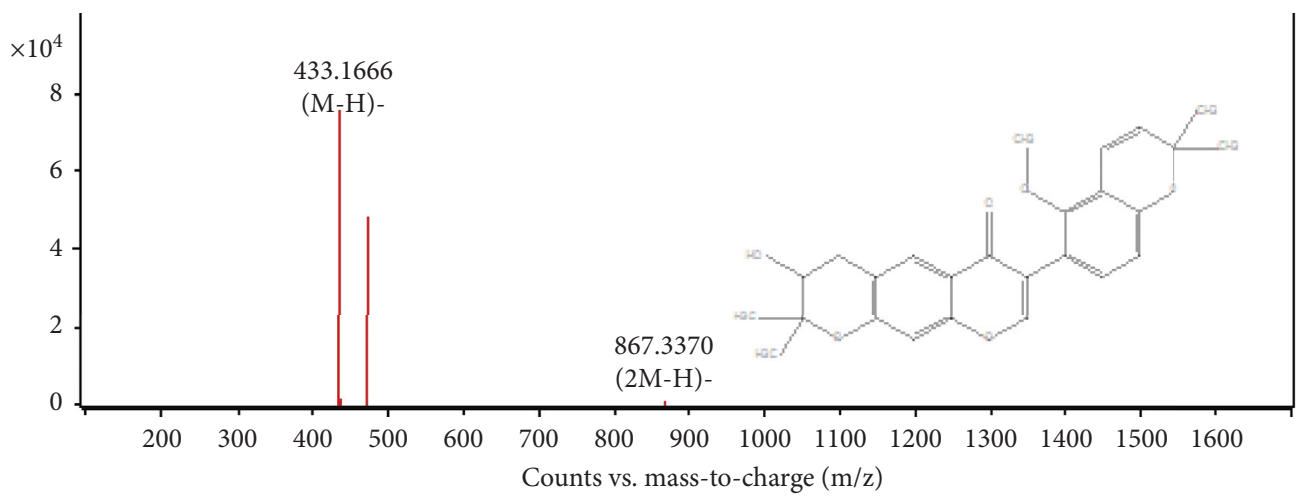

(g)

FIGURE 4: Molecular ion from LC-MS chromatogram screening of the C. latifolia root extract. (a) hydroquinone, (b) phloridzin, (c) dimethyl caffeic acid, (d) pomiferin, (e) scandenin, (f) monobenzone, and (g) mundulone.

established in this study revealed that SWE is a green technique for powerful extraction of C. latifolia extracts without using toxic solvents, which can be widely applied in pharmaceutical studies, even at an industrial scale.

\section{Conclusions}

Temperature and time obviously affected the total phenolic, total flavonoid, and antioxidant activity of the C. latifolia root extract. The results demonstrated the highest phenolic, flavonoid, and antioxidant activity at $180^{\circ} \mathrm{C}$ and at $30 \mathrm{~min}$ of extraction time. At this point, the result gives the highest antioxidant activity with the highest percentage of inhibition activity. On the other hand, these results were well correlated with the TPC and TFC. Furthermore, it is worthy to note that the DPPH assay gives better correlation results for TPC and TFC compared with the ABTS assay. The optimum condition of SWE was demonstrated at $180^{\circ} \mathrm{C}$ at $30 \mathrm{~min}$ of extraction time and that above $180^{\circ} \mathrm{C}$, degradation of phenolic and flavonoid compounds occurred. The C. latifolia root extract could be useful as a good source of antioxidative materials. Furthermore, SWE can be one of the most efficient extraction techniques for the production of antioxidative materials from a plant extract. The results are given in LC-MS analysis and the antioxidant activity for C. latifolia plants make us reflect on the ethnomedical usages as well as the therapeutic values that could be useful in promoting better nutrition and preventing oxidative stress-related diseases. A further investigation of this natural product is still required, particularly the bioactive components that could be an attractive source of nutraceutical ingredients.

\section{Data Availability}

The data used to support the findings of this study are available from the corresponding author upon request.

\section{Conflicts of Interest}

The authors declare no conflicts of interest.

\section{Acknowledgments}

The authors acknowledge the financial support of the Malaysian Ministry of Higher Education for Fundamental Research Grant Scheme, FRGS (Project no: 04-01-161861FR), and the Institute of Bioscience, Universiti Putra Malaysia, for providing laboratory facilities.

\section{References}

[1] M. H. H. Roby, M. A. Sarhan, K. A.-H. Selim, and K. I. Khalel, "Evaluation of antioxidant activity, total phenols and phenolic compounds in thyme (Thymus vulgaris L.), sage (Salvia officinalis L.), and marjoram (Origanum majorana L.) extracts," Industrial Crops and Products, vol. 43, pp. 827-831, 2013.

[2] S. Phoboo, K. Shetty, and T. ElObeid, "In vitro assays of antidiabetic and anti-hypertensive potential of some traditional edible plants of Qatar," Journal of Medicinally Active Plants, vol. 4, no. 3, pp. 22-29, 2015.

[3] X. Liu, L. Jia, Y. Gao, B. Li, and Y. Tu, "Anti-inflammatory activity of total flavonoids from seeds of Camellia oleifera abel," Acta Biochimica et Biophysica Sinica, vol. 46, no. 10, pp. 920-922, 2014.

[4] A. A. Alimi and A. O. T. Ashafa, "An in vitro evaluation of the antioxidant and antidiabetic potential of Sutherlandia montana E. Phillips \& R.A. Dyer leaf extracts," Asian Pacific Journal of Tropical Biomedicine, vol. 7, no. 9, pp. 765-772, 2017.

[5] S. B. Nimse and D. Pal, "Free radicals, natural antioxidants, and their reaction mechanisms," RSC Advances, vol. 5, no. 35, pp. 27986-28006, 2015.

[6] M. Carocho and I. C. F. R. Ferreira, "A review on antioxidants, prooxidants and related controversy: natural and synthetic compounds, screening and analysis methodologies and future perspectives," Food and Chemical Toxicology, vol. 51, pp. 15-25, 2013.

[7] M. H. AL-Zuaidy, A. Ismail, S. Mohamed, A. F. A. Razis, M. W. Mumtaz, and A. A. Hamid, "Antioxidant effect, glucose uptake activity in cell lines and cytotoxic potential of melicope lunu-ankenda leaf extract," Journal of Herbal Medicine, vol. 14, pp. 55-60, 2018.

[8] E. B. Mojzer, M. K. Hrnčič, M. Škerget, Ž. Knez, and U. Bren, "Polyphenols: extraction methods, antioxidative action, bioavailability and anticarcinogenic effects," Molecules, vol. 21, no. 7, p. 901, 2016. 
[9] N. Nastić, J. Švarc-Gajić, C. Delerue-Matos et al., "Subcritical water extraction as an environmentally-friendly technique to recover bioactive compounds from traditional Serbian medicinal plants," Industrial Crops and Products, vol. 111, pp. 579-589, 2018.

[10] P. S. Saravana, A. Tilahun, C. Gerenew et al., "Subcritical water extraction of fucoidan from Saccharina japonica: optimization, characterization and biological studies," Journal of Applied Phycology, vol. 30, no. 1, pp. 579-590, 2018.

[11] J. H. Lee, M. J. Ko, and M. S. Chung, "Subcritical water extraction of bioactive components from red ginseng (Panax ginseng C.A. Meyer)," The Journal of Supercritical Fluids, vol. 133, pp. 177-183, 2018.

[12] M. V. Kiamahalleh, G. Najafpour-Darzi, M. Rahimnejad, A. A. Moghadamnia, and M. V. Kiamahalleh, "High performance curcumin subcritical water extraction from turmeric (Curcuma longa L.)," Journal of Chromatography B, vol. 1022, pp. 191-198, 2016.

[13] Z. Zhang, S. Baroutian, M. T. Munir, and B. R. Young, "Variation in metals during wet oxidation of sewage sludge," Bioresource Technology, vol. 245, pp. 234-241, 2017.

[14] The Plant List Version 1.1, 2013, http://www.theplantlist.org/.

[15] I. I. Hejazi, R. Khanam, S. H. Mehdi et al., "Antioxidative and anti-proliferative potential of Curculigo orchioides Gaertn in oxidative stress induced cytotoxicity: in vitro, ex vivo and in silico studies," Food and Chemical Toxicology, vol. 115, pp. 244-259, 2018.

[16] N. A. Ishak, M. Ismail, M. Hamid, Z. Ahmad, and S. A. Abd Ghafar, "Antidiabetic and hypolipidemic activities of Curculigo latifolia fruit: root extract in high fat fed diet and low dose STZ induced diabetic rats," Evidence-Based Complementary and Alternative Medicine, vol. 2013, Article ID 601838, 12 pages, 2013.

[17] D. J. Ooi, K. W. Chan, N. Ismail, M. U. Imam, and M. Ismail, "Polyphenol-rich ethyl acetate fraction of Molineria latifolia rhizome restores oxidant-antioxidant balance by possible engagement of KEAP1-NRF2 and $\mathrm{PKC} / \mathrm{NF}-\kappa \mathrm{B}$ signalling pathways," Journal of Functional Foods, vol. 42, pp. 111-121, 2018.

[18] S. R. Fatemeh, R. Saifullah, F. M. A. Abbas, and M. E. Azhar, "Total phenolics, flavonoids and antioxidant activity of banana pulp and peel flours: influence of variety and stage of ripeness," International Food Research Journal, vol. 19, no. 3, p. 1041, 2012.

[19] K. W. Chan, N. M. H. Khong, S. Iqbal, and M. Ismail, "Simulated gastrointestinal $\mathrm{pH}$ condition improves antioxidant properties of wheat and rice flours," International Journal of Molecular Sciences, vol. 13, no. 6, pp. 7496-7507, 2012.

[20] H. Tohma, İ Gülçin, E. Bursal, A. C. Gören, S. H. Alwasel, and E. Köksal, "Antioxidant activity and phenolic compounds of ginger (Zingiber officinale Rosc.) determined by HPLC-MS/ MS," Journal of Food Measurement and Characterization, vol. 11, no. 2, pp. 556-566, 2017.

[21] R. Song, M. Ismail, S. Baroutian, and M. Farid, "Effect of subcritical water on the extraction of bioactive compounds from carrot leaves," Food and Bioprocess Technology, vol. 11, no. 10, pp. 1895-1903, 2018.

[22] E. Ö. Kanmaz and Ö. Saral, "The relationship between antioxidant activities and phenolic compounds of the subcritical water extracts from orange peel," GIDA/The Journal of Food, vol. 42, no. 5, pp. 485-493, 2017.

[23] H. Xu, W. Wang, X. Liu, F. Yuan, and Y. Gao, “Antioxidative phenolics obtained from spent coffee grounds (Coffea arabica
L.) by subcritical water extraction," Industrial Crops and Products, vol. 76, pp. 946-954, 2015.

[24] S. Erşan, Ö. G. Üstündağ, R. Carle, and R. M. Schweiggert, "Subcritical water extraction of phenolic and antioxidant constituents from pistachio (Pistacia vera L.) hulls," Food Chemistry, vol. 253, pp. 46-54, 2018.

[25] M. J. Ko, C. I. Cheigh, S. W. Cho, and M. S. Chung, "Subcritical water extraction of flavonol quercetin from onion skin," Journal of Food Engineering, vol. 102, no. 4, pp. 327-333, 2014.

[26] J. H. Lee, K. H. Park, M.-H. Lee et al., "Identification, characterisation, and quantification of phenolic compounds in the antioxidant activity-containing fraction from the seeds of Korean perilla (Perilla frutescens) cultivars," Food Chemistry, vol. 136, no. 2, pp. 843-852, 2013.

[27] A. Cvetanović, J. Švarc-Gajić, U. Gašić et al., "Isolation of apigenin from subcritical water extracts: optimization of the process," The Journal of Supercritical Fluids, vol. 120, pp. 32-42, 2017.

[28] D. Ooi, K. Chan, N. Sarega, N. Alitheen, H. Ithnin, and M. Ismail, "Bioprospecting the curculigoside-cinnamic acidrich fraction from molineria latifolia rhizome as a potential antioxidant therapeutic agent," Molecules, vol. 21, no. 6, p. 682, 2016.

[29] D. Lachos-Perez, A. M. Baseggio, P. C. Mayanga-Torres et al., "Subcritical water extraction of flavanones from defatted orange peel," The Journal of Supercritical Fluids, vol. 138, pp. 7-16, 2018.

[30] A. Cvetanović, G. Zengin, Z. Zeković et al., "Comparative in vitro studies of the biological potential and chemical composition of stems, leaves and berries Aronia melanocarpa's extracts obtained by subcritical water extraction," Food and Chemical Toxicology, vol. 121, pp. 458-466, 2018.

[31] D. Setyorini, R. Aanisah, S. Machmudah et al., "Extraction of phytochemical compounds from eucheuma cottonii and gracilaria sp using supercritical $\mathrm{CO}_{2}$ followed by subcritical water," MATEC Web of Conferences, vol. 156, p. 03051, 2018.

[32] L. He, X. Zhang, H. Xu et al., "Subcritical water extraction of phenolic compounds from pomegranate (Punica granatum L.) seed residues and investigation into their antioxidant activities with HPLC-ABTS+ assay," Food and Bioproducts Processing, vol. 90, no. 2, pp. 215-223, 2012.

[33] R. Pandey and B. Kumar, "HPLC-QTOF-MS/MS-based rapid screening of phenolics and triterpenic acids in leaf extracts of Ocimum species and their interspecies variation," Journal of Liquid Chromatography \& Related Technologies, vol. 39, no. 4, pp. 225-238, 2016.

[34] U. Kankeaw and E. Masong, "The antioxidant activity from hydroquinone derivatives by the synthesis of Cinnamomium verum J. Presl Bark's extracted," International Journal of Chemical Engineering and Applications, vol. 6, no. 2, pp. 9195, 2015.

[35] D. Guardado-Félix, S. O. Serna-Saldivar, E. O. CuevasRodríguez, D. A. Jacobo-Velázquez, and J. A. GutiérrezUribe, "Effect of sodium selenite on isoflavonoid contents and antioxidant capacity of chickpea (Cicer arietinum L.) sprouts," Food Chemistry, vol. 226, pp. 69-74, 2017.

[36] A. Baldisserotto, G. Malisardi, E. Scalambra et al., "Synthesis, antioxidant and antimicrobial activity of a new phloridzin derivative for dermo-cosmetic applications," Molecules, vol. 17, no. 11, pp. 13275-13289, 2012.

[37] A. Francini and L. Sebastiani, "Phenolic compounds in apple (Malus x domestica Borkh.): compounds characterization and stability during postharvest and after processing," Antioxidants, vol. 2, no. 3, pp. 181-193, 2013. 

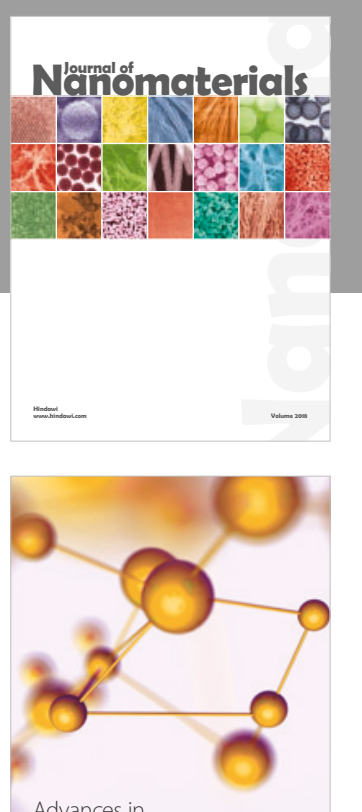

Physical Chemistry
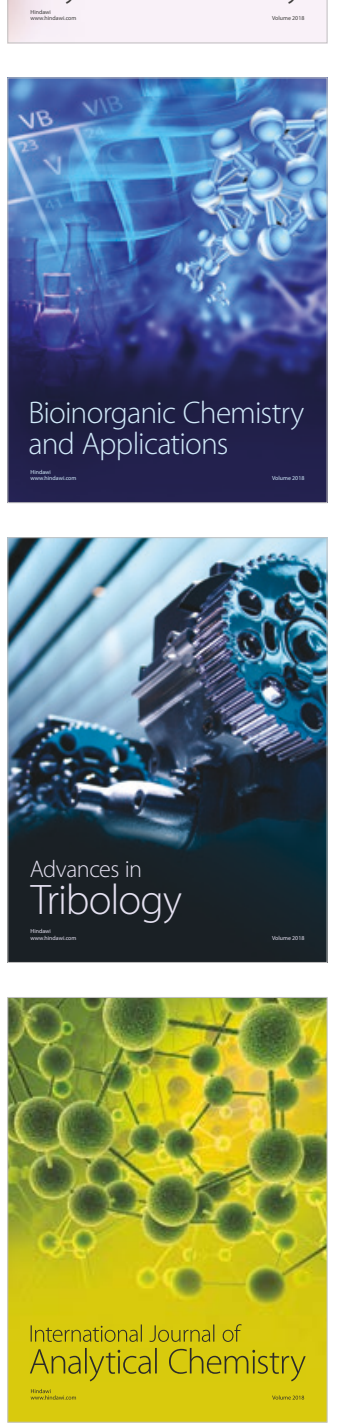

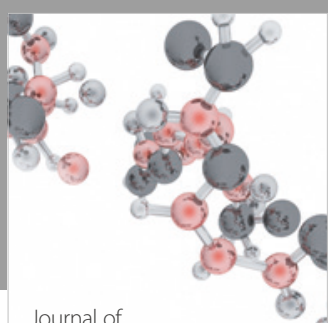

Analytical Methods

in Chemistry

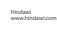

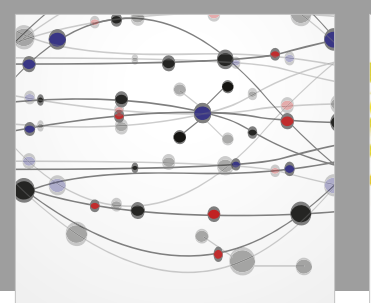

The Scientific World Journal

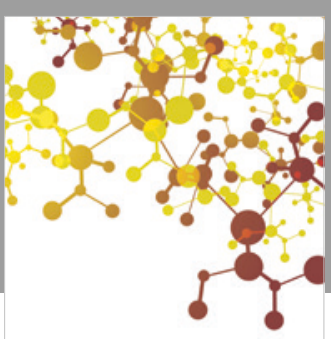

Journal of

Applied Chemistry
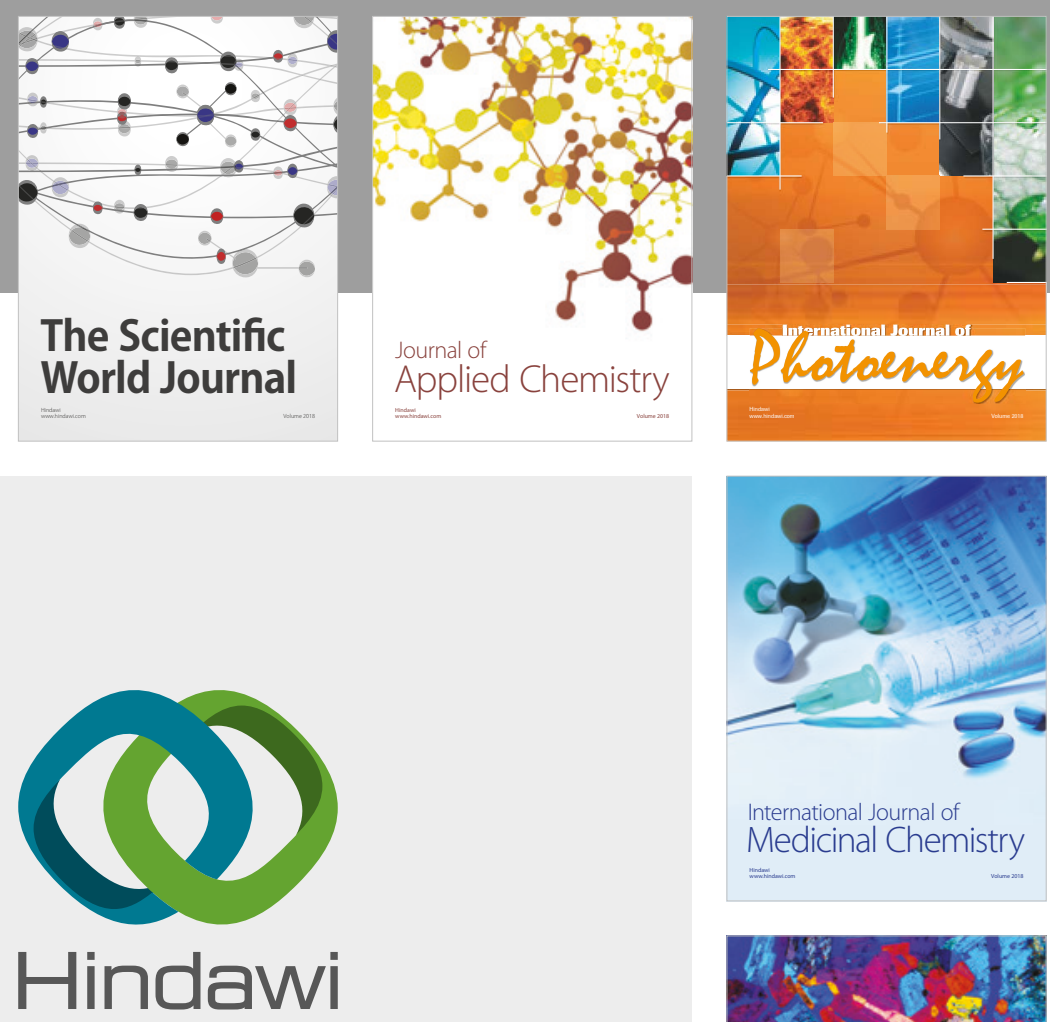

Submit your manuscripts at

www.hindawi.com
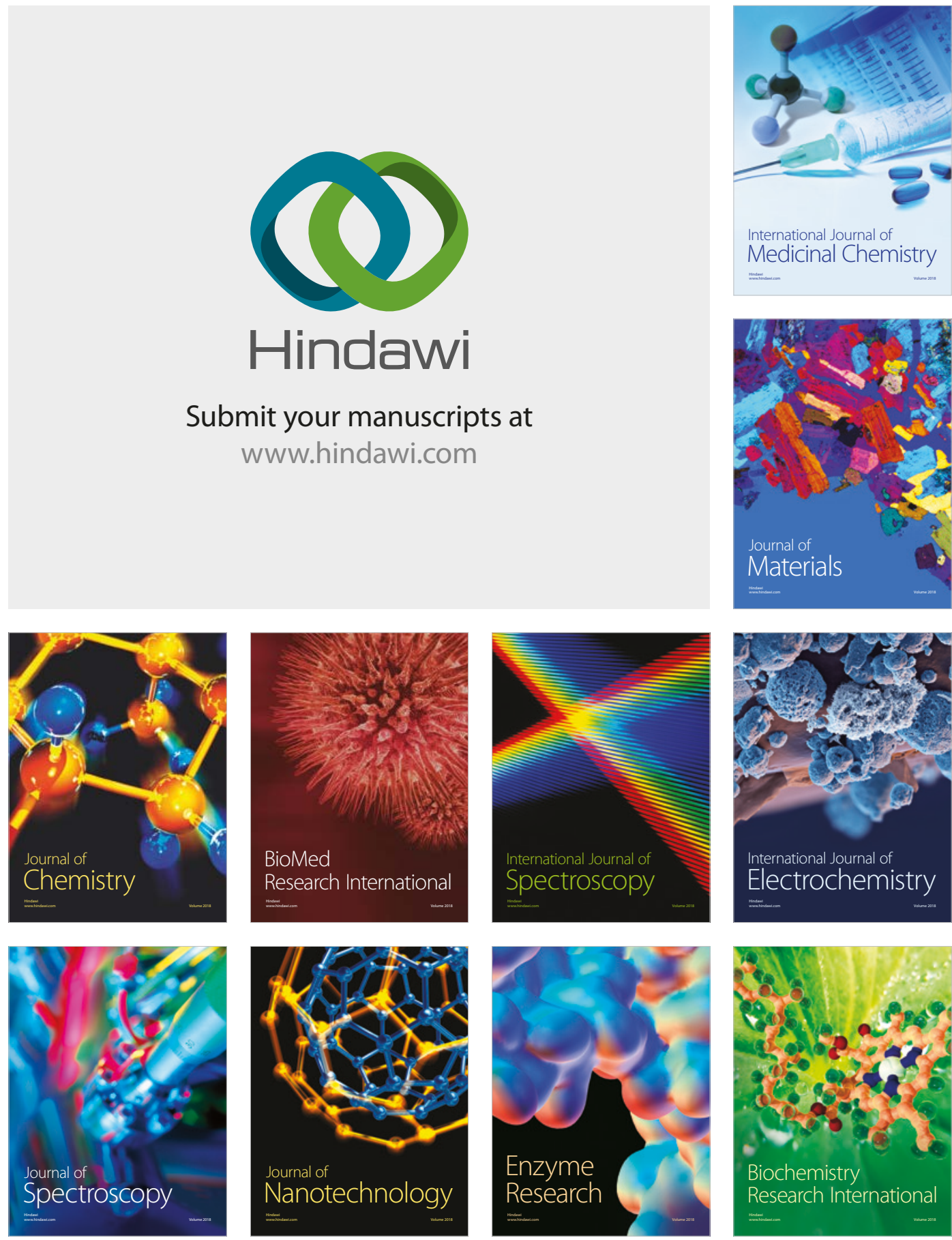
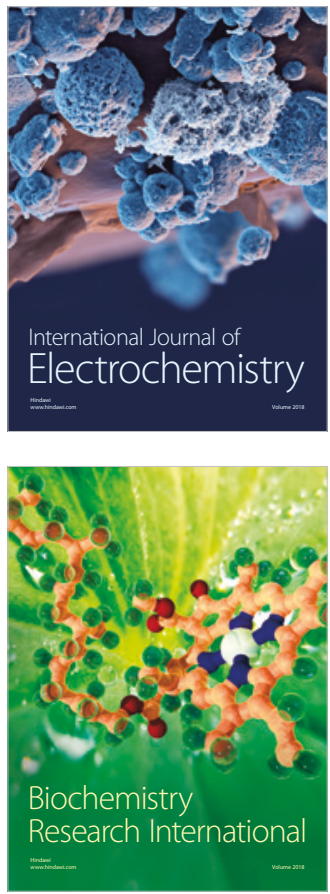